\title{
Endoscopic placement of multiple artificial chordae with robotic assistance and nitinol clip fixation
}

\author{
J. Michael Smith, MD, ${ }^{a}$ and Hubert Stein, BSc, BME ${ }^{\mathrm{b}}$
}

Objective: A totally endoscopic method of placing multiple premeasured artificial chordae with the assistance of the da Vinci surgical system (Intuitive Surgical Inc, Sunnyvale, Calif) and V60 U-clip devices (Medtronic Inc, Minneapolis, Minn) was evaluated.

Methods: Totally endoscopic placement of multiple artificial chordae with robotic assistance and nitinol clips was performed in 30 patients. After subvalvular exposure with a robotically controlled Atrial Retractor (Intuitive Surgical Inc), artificial chordae constructed of 4-0 polytetrafluoroethylene (Gore-Tex; WL Gore \& Associates Inc, Flagstaff, Ariz) were secured to the prolapsing leaflet edge with V60 U-clips. Transesophageal echocardiography to assess successful repair was performed.

Results: Repairs of the anterior leaflet, the posterior leaflet, and combinations of both were performed. Crossclamp and cardiopulmonary bypass times were in the range of $78.63 \pm 17.03$ minutes and $118.17 \pm 22.55$ minutes, respectively. Transesophageal echocardiography showed grade 0 to less than grade 1 mitral regurgitation postoperatively. All patients had an uneventful recovery phase and were discharged within 5 days.

Conclusion: Endoscopic placement of premeasured artificial neochordae is greatly facilitated by applying robotic assistance and using nitinol clips for chordae fixation. The endoscopic robotic technique provides excellent functional and clinical outcomes.

From the Department of Surgery, Good Samaritan Hospital, ${ }^{\text {a }}$ Cincinnati, Ohio; and Intuitive Surgical Inc, Clinical Development Engineering, ${ }^{\mathrm{b}}$ Sunnyvale, California.

Dr Smith reports consulting and lecture fees from Intuitive Surgical Inc. Mr Stein reports equity ownership and employment by Intuitive Surgical Inc.

Received for publication June 11, 2007; revisions received Oct 8, 2007; accepted for publication Oct 15, 2007.

Address for reprints: J. Michael Smith, MD, c/o Amy Engel, Hatton Institute, Good Samaritan Hospital, 375 Dixmyth Ave, Cincinnati, OH 45220 (E-mail: amy_engel@ trihealth.com).

J Thorac Cardiovasc Surg 2008;135:610-4 $0022-5223 / \$ 34.00$

Copyright $\odot 2008$ by The American Association for Thoracic Surgery

doi:10.1016/j.jtcvs.2007.10.041
$\mathrm{A}$ variety of methods have been described for the placement of artificial chordae with expanded polytetrafluoroethylene (Gore-Tex; WL Gore \& Associates Inc, Flagstaff, Ariz) to correct anterior and posterior leaflet prolapse and treat diseased mitral valve chordae. ${ }^{1-5}$ However, it is infrequently applied because of the technical challenges encountered, especially when performed through minimally invasive video-assisted thoracotomy approaches. Because of limitations created by 2-dimensional video vision, compromised exposure with static manual retractors, ${ }^{6}$ and limited degrees of freedom of standard thoracoscopic instrumentation, anchoring the neochordae precisely in the papillary muscle and securing the sutures through the leaflets are often challenging.

We describe a totally endoscopic method of placing multiple premeasured artificial chordae with the assistance of the da Vinci surgical system (Intuitive Surgical Inc, Sunnyvale, Calif) and using V60 U-clips (Medtronic Inc, Minneapolis, Minn) to overcome these limitations.

\section{Materials and Methods}

Between August of 2006 and February of 2007, 30 patients with severe mitral insufficiency and bileaflet mitral valve prolapse were included in the study (Table 1). Institutional review board approval was obtained for all patients to collect the data presented.

Nifong and associates ${ }^{7}$ described the basic method of robotic mitral valve repair in a large series. We use a more lateral approach, as illustrated in detail elsewhere. ${ }^{6,8}$ In brief, the entire operation was performed through 5 right thoracoscopic ports ranging in size from 8 to $20 \mathrm{~mm}$. 


\section{Abbreviation and Acronym}

TEE $=$ transesophageal echocardiography

Pericardiotomy is performed, cardiopulmonary bypass is initiated, and aortic occlusion is achieved. After left atriotomy, the mitral valve is exposed using a robotically controlled EndoWrist atrial retractor (Intuitive Surgical Inc). ${ }^{6}$ After the mitral valve anatomy is assessed, the prolapsing segment is identified with valve hooks. The "ski-tip"-style ends of the robotic retractor blades are lodged into the anterior leaflet, and the atrial septum is lifted until the papillary muscles can be visualized clearly.

To determine the required length of the artificial chordae loops, the distance between the correct plane of apposition on an adjacent normal nonprolapsing segment of the mitral leaflet and the respective papillary muscle is measured. This is done with a Mohr Suture Ruler device (03-5409; Geister, Tuttlingen, Germany) and confirmed by comparison with preoperative transesophageal echocardiography (TEE). Artificial chordae with 4 loops each are then constructed of 4-0 polytetrafluoroethylene (Gore-Tex) per the technique described by von Oppell and Mohr. ${ }^{2}$ A single felt pledget builds the platform with multiple neochords of definite length extending from its base.

Both free suture needles from the pledget platform are passed through the respective papillary muscle with 2 robotic large needle drivers. After confirmation of correct placement in the muscle head, the needles are retrieved and the neochordae platform is secured with extracorporeal knots tied by the patient side assistant using a closed knot pusher (Closed Macro Knot Pusher M4503P, Cooper Surgical Inc, Trumbull, Conn) (Figure 1). There is always the potential risk of cutting off the papillary muscle by overtightening the
TABLE 1. Patient characteristics

\begin{tabular}{lc}
\hline \multicolumn{1}{c}{ Variable } & Data \\
\hline No. of patients & 30 \\
Gender & \\
Men & $18(60 \%)$ \\
Women & $12(40 \%)$ \\
Age (y) & $57.2 \pm 12.9$ \\
& range $(34-85)$ \\
AFIB & $5(16.7 \%)$ \\
NYHA & \\
Class 1 & $1(3.3 \%)$ \\
Class 2 & $13(13.3 \%)$ \\
Class 3 & $16(53.3 \%)$ \\
Class 4 & $0(0 \%)$ \\
Ejection fraction & \\
$>55 \%$ & 7 \\
$40 \%-50 \%$ & 19 \\
$30 \%-40 \%$ & 3 \\
$<30 \%$ & 1 \\
\hline
\end{tabular}

AFIB, Atrial fibrillation; NYHA, New York Heart Association.

anchor stitches on the loop platform. This is avoided by maintaining a suture gap between the muscle head and the polytetrafluoroethylene (Gore-Tex) knot with the robotic large needle holder while the patient side assistant performs the knot tying (Figure 1). Figure 2 shows the neochordae platform anchored in the papillary muscle head.

To secure each premeasured neochordae loop to the edge of the prolapsing leaflet, a single-armed V60 U-clip was applied per loop. The U-clip is made of nitinol, a material that allows the clip to return to a preformed circular shape after deployment. Once the correct
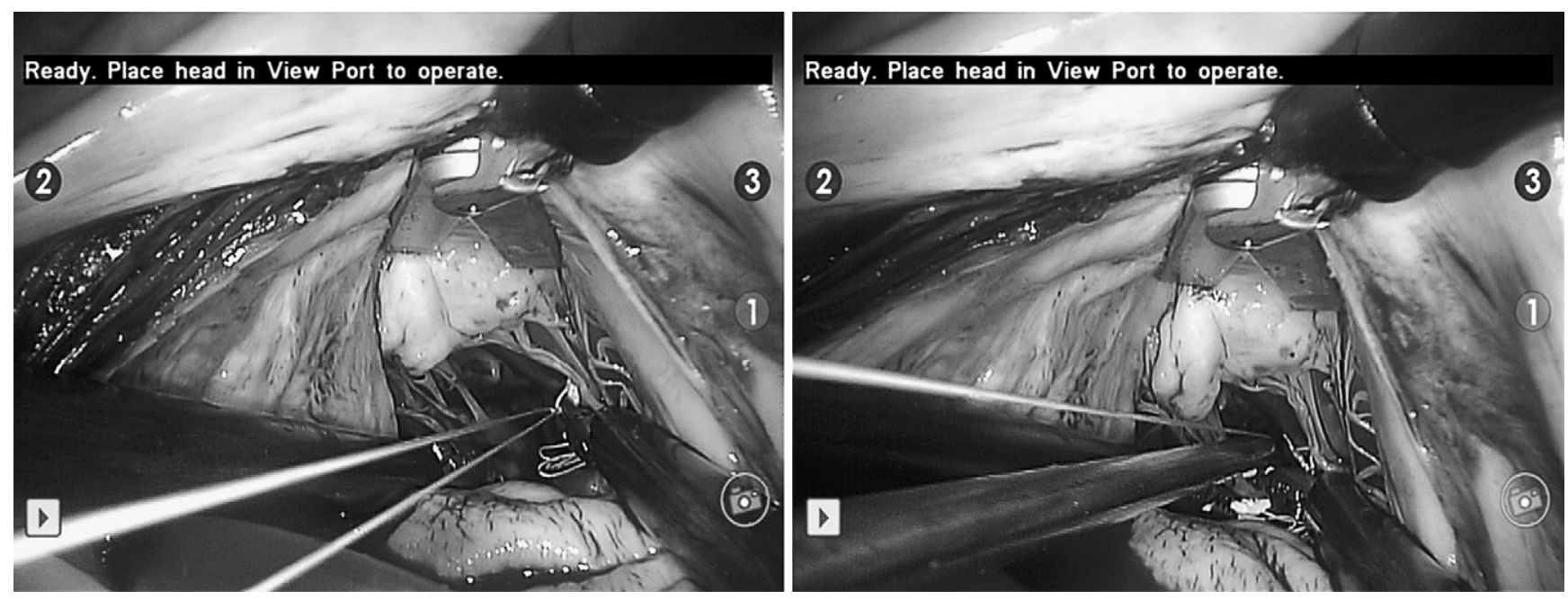

Figure 1. The neochordae platform is secured with extracorporeal knots tied by the patient side assistant using a closed knot pusher. Right robotic large needle holder maintains a suture gap between the muscle head and the polytetrafluoroethylene (Gore-Tex; WL Gore \& Associates Inc, Flagstaff, Ariz) knot to avoid cutting off the papillary muscle by overtightening the anchor stitches on the loop platform. The atrial retractor (top) provides deep subvalvular exposure. 


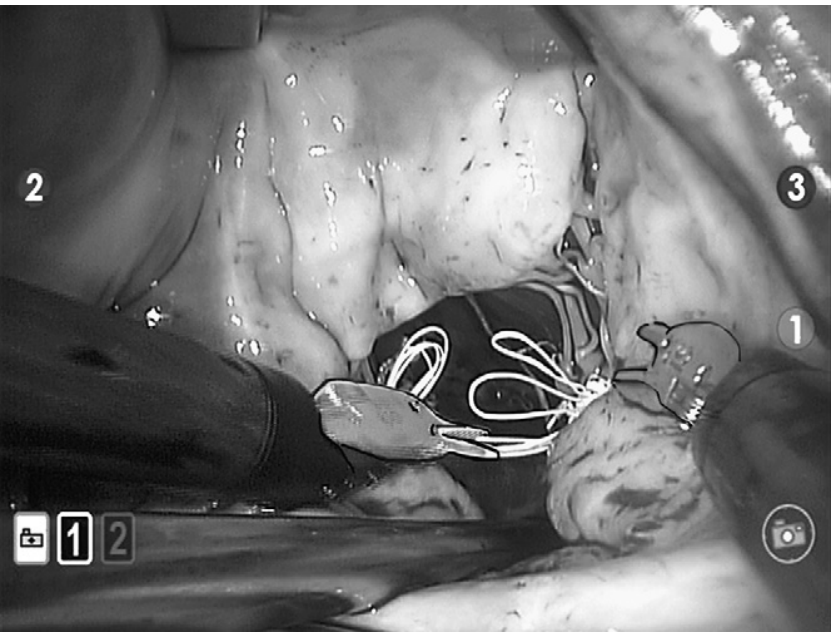

Figure 2. Two sets of neochordae anchored on the posterior surface of the anterolateral papillary muscle and the posteromedial papillary muscle for repair of a large P2 prolapse. The multiple loops going up from the platform are clearly visible.

plane of leaflet coaptation is confirmed under high-definition 3-dimensional vision, the single-armed U-clip is placed in the leaflet edge with a robotic large needle holder and the neochordae loop is captured in the open clip circle. The U-clip is deployed by pulling the needle off the clip portion and securing the neochordae loop to the leaflet. Additional reduction of the leaflet height (compared with a normal adjacent section) can be achieved by folding the leaflet edge toward the ventricle before deploying the U-clip (Figure 3 ). The remaining loops are then distributed at equal distance along the edge of the prolapsed segment by applying the same technique. For bileaflet prolapse repairs, 1 set of neochordae loops is used to correct the posterior leaflet prolapse. After the pledget platform is secured (the needles are kept on the 4-0 polytetrafluoroethylene [Gore-Tex] suture), the 2 free suture needles are placed through the anterior leaflet twice (double loop) to correct the anterior prolapse. Once correct apposition is confirmed (saline test), the patient side assistant ties the knot as previously described. In addition, 29 patients received a posterior annuloplasty band. One patient did not receive an annuloplasty band at the surgeon's discretion because of advanced age and heavy calcification of the annulus. The technique for annuloplasty band fixation has been described in detail elsewhere. 9,10

For concomitant left atrial ablation, a SurgiFlex XL probe (Cryocath, Montreal, Quebec, Canada) was applied endocardially. In 4 patients, an encircling lesion plus a mitral annulus connection lesion was performed. In these same 4 patients and 1 patient in long-standing atrial fibrillation (no cryoablation performed), the left atrial appendage was closed robotically with a running 4-0 polytetrafluoroethylene (Gore-Tex) suture.

Lastly, the heart is de-aired and the left atrium is closed with a running suture line. TEE was performed at the conclusion of surgery to assess successful repair.

\section{Results}

Posterior leaflet prolapse was repaired in 24 patients, isolated anterior leaflet prolapse was repaired in 3 patients, and bileaf-

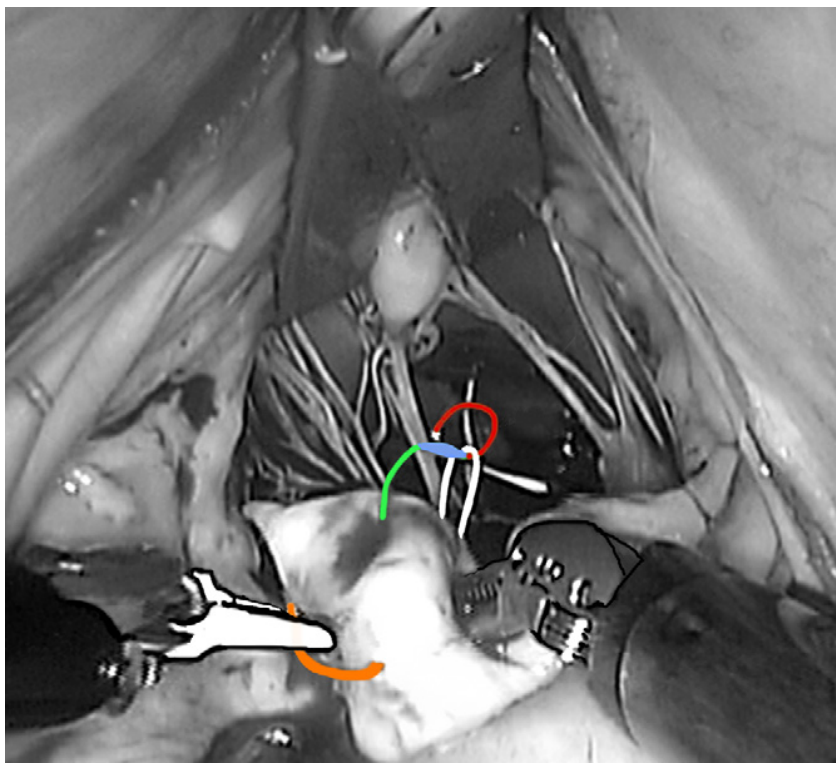

Figure 3. U-clip device (Medtronic Inc, Minneapolis, Minn) (red, release trigger: blue, braided member: green, needle: orange) is placed in the leaflet with a robotic large needle holder, and the neochordae loop (white) is captured in the open clip circle. In this patient, the leaflet edge is folded toward the ventricle before deploying the $\mathrm{U}$-clip device to achieve additional reduction of the leaflet height. The "ski-tip"-style ends of the robotic atrial retractor blades are lodged into the anterior leaflet, and the papillary muscles are visualized clearly.

let prolapse was repaired in 3 patients. The number of neochordae sets used per patient depended on the prolapse status of the impaired leaflets. For correction of the diverse leaflets prolapsed, either 1 or 2 sets were attached. The deep subvalvular dynamic exposure provided by the robotically controlled atrial retractor made placement of the neochordae loops feasible in all patients. Table 2 summarizes the neochordae placement strategy applied in this series.

Crossclamp and cardiopulmonary bypass times were in the range of $78.63 \pm 17.03$ minutes and $118.17 \pm 22.55 \mathrm{~min}-$ utes, respectively. TEE showed no mitral regurgitation in 26 patients and less than grade 1 mitral regurgitation in 4 patients postoperatively. Four patients received a concomitant cryoablation, and closure of the left atrial appendage was performed. One patient with long-standing atrial fibrillation had the left atrial appendage closed but did not receive cryoablation. All patients had an uneventful recovery phase and were discharged within 5 days. The results are summarized in Table 3.

\section{Discussion}

Placing multiple premeasured artificial chordae for anterior and posterior leaflet prolapse has been shown to be an effective repair option for mitral regurgitation. By using robotic 
TABLE 2. Artificial neo-chordae placement strategy

\begin{tabular}{|c|c|c|c|}
\hline Repaired MV leaflet & Prolapsed leaflet segment & Neochordae loop distribution & Pledgeted platform orientation \\
\hline \multirow[t]{3}{*}{ Posterior $\mathrm{N}=24$} & $\mathrm{P} 2 \mathrm{~N}=22$ & $\begin{array}{l}\mathrm{N}=2: 2 \text { sets of neochordae with loops evenly } \\
\text { distributed to each papillary muscle }\end{array}$ & PS of ALPM and PMPM \\
\hline & & $\mathrm{N}=20: 1$ set of neochordae & PS of ALPM or PMPM \\
\hline & $\mathrm{P} 3 \mathrm{~N}=2$ & 1 set of neochordae with all loops to PMPM & PS of PMPM \\
\hline \multirow[t]{2}{*}{ Anterior $\mathrm{N}=3$} & $\mathrm{~A} 1-\mathrm{A} 2-\mathrm{A} 3 \mathrm{~N}=1$ & $\begin{array}{l}2 \text { sets of neochordae with loops evenly } \\
\text { distributed to each papillary muscle }\end{array}$ & AS of ALPM and PMPM \\
\hline & $\mathrm{A} 2-\mathrm{A} 3 \mathrm{~N}=2$ & 1 set of neochordae & AS of ALPM or PMPM \\
\hline \multirow[t]{2}{*}{ Bileaflet $\mathrm{N}=3$} & $\mathrm{P} 2-\mathrm{A} 2 \mathrm{~N}=1$ & $\begin{array}{l}1 \text { set of neochordae with loops to PMPM } \\
\text { Anterior repair with "anchor" suture from platform }\end{array}$ & PS of PMPM \\
\hline & P3-A3 N = 2 & $\begin{array}{l}1 \text { set of neochordae with all loops to PMPM. } \\
1 \text { set of neochordae with loops to PMPM } \\
\text { Anterior repair with "anchor" suture from platform }\end{array}$ & PS of PMPM \\
\hline
\end{tabular}

$A L P M$, Anterolateral papillary muscle; $P M P M$, posteromedial papillary muscle; $P S$, posterior surface; $A S$, anterior surface; $M V$, mitral valve.

assistance and nitinol clips, placement of premeasured artificial neochordae is facilitated. The "Mohr" technique, ${ }^{2}$ used to create the "premeasured" chordal loops, avoids overshortening and obviates adjustment of the chords after placement, and has led to an increase in the nonresectional approach to posterior leaflet prolapse in our institution. Double-armed U-clip devices are already commonly used during robotic mitral valve repair mainly for ring fixation. ${ }^{11}$ They have proven to be more time efficient and easier to secure when placing annuloplasty bands compared with standard suturing. In a recent study, no significant difference was found between band dehiscence when using the U-clip versus suture fixation. ${ }^{12}$ To our knowledge, embolization has not been reported to date using these clips. The use of singlearmed U-clips in off-pump coronary artery bypass cases for 112 distal anastomoses in another study enabled a safe, definite, and rapid connection of arterial grafts, and the clips were considered a useful alternative to standard suture material. ${ }^{13}$ With the single-armed V60 U-clips, time-consuming knot tying is avoided when securing the artificial chordae loops to the leaflet edge.

With the recent introduction of the robotic-controlled atrial retractor into our surgical practice, we observed a reduction in crossclamp and bypass times in the range of 20

\section{TABLE 3. Operative results}

\begin{tabular}{lc}
\hline \multicolumn{1}{c}{ Variable } & Data \\
\hline Crossclamp time (min) & $78.63 \pm 17.03$ (range 54-124) \\
CPB time & $118.17 \pm 22.55$ (range 85-189) \\
Length of stay (d) & $3.9 \pm 0.6$ (range 3-5) \\
TEE at discharge & $26(86.7 \%)$ \\
No MR & $4(13.3 \%)$ \\
Trace MR $(<$ grade 1) & $4(13.3 \%)$ \\
Concomitant cryoablation & $5(16.67 \%)$ \\
Closure of left atrial appendage &
\end{tabular}

$\mathrm{CPB}$, Cardiopulmonary bypass; TEE, transesophageal echocardiography; $M R$, mitral regurgitation. minutes compared with data from our multicenter study. ${ }^{6}$ The described surgical technique using premeasured neochordae, robotic assistance, and nitinol clips has further reduced these critical times by approximately 13 minutes for crossclamp time and 37 minutes for cardiopulmonary bypass.

The initial measurement of the proper chordal height for creation of the neochordae is facilitated by the 3-dimensional vision of the da Vinci surgical system. The correct plane of apposition for the prolapsing segment can be assessed with higher confidence compared with 2-dimensional video vision.

Subvalvular work at the papillary muscle head is greatly improved because of the capability of dynamically exposing the mitral valve during the procedure with the robotic atrial retractor. ${ }^{6}$ The increased dexterity provided by the robotic instrumentation facilitates the placement of the pledgeted platform in any desired orientation.

\section{Conclusions}

The ability to perform complex mitral valve repairs totally endoscopically has been questioned or deemed to be impossible. In our experience, the described method of placing multiple premeasured artificial neochordae endoscopically with the assistance of robotics and nitinol clips has facilitated and improved mitral valve repair techniques, allowing excellent outcomes even in complex repairs, and shifted our repair strategy to a nonresectional approach for most leaflet pathologies.

The authors thank Amy M. Engel, MA (Hatton Research Institute, Cincinnati, Ohio), for support during the study, and Sarah L. Tran (San Francisco, Calif), for the artwork presented in the article.

\section{References}

1. David TE, Omran A, Armstrong S, Sun Z, Ivanov J. Long-term results of mitral valve repair for myxomatous disease with and without chordal replacement with expanded polytetrafluoroethylene sutures. $J$ Thorac Cardiovasc Surg. 1998;115:1279-86. 
2. von Oppell UO, Mohr FW. Chordal replacement for both minimally invasive and conventional mitral valve surgery using premeasured Gore-Tex loops. Ann Thorac Surg. 2000;70:2166-8.

3. Dang NC, Stewart AS, Kay J, Mercando ML, Kruger KH, Topkara VK, et al. Simplified placement of multiple artificial mitral valve chords. Heart Surg Forum. 2005;8:E129-31 [Epub April 2005].

4. Calafiore AM. Choice of artificial chordae length according to echocardiographic criteria. Ann Thorac Surg. 2006;81:375-7.

5. Tam R, Joshi P, Konstantinov IE. A simple method of preparing artificial chordae for mitral valve repair. J Thorac Cardiovasc Surg. 2006;132: 1486-7.

6. Smith JM, Stein H, Engel AM, McDonough S, Lonneman L. Totally endoscopic mitral valve repair utilizing a robotic controlled atrial retractor. Ann Thorac Surg. 2007;84:633-7.

7. Nifong LW, Reade CC, Chitwood WR. 200 Consecutive robotic mitral valve repairs. Circulation. 2005;112(17 pt II):496.

8. Murphy DA, Miller JS, Langford DA, Snyder AB. Endoscopic robotic mitral valve surgery. $J$ Thorac Cardiovasc Surg. 2006;132: 776-81.
9. Reade CC, Bower CE, Bailey M, Maziarz DM, Masroor S, Kypson AP, et al. Robotic mitral annuloplasty with double-arm Nitinol u-clips. Ann Thorac Surg. 2005;79:1372-7.

10. Cook RC, Nifong LW, Enterkin JE, Charland PJ, Reade CC, Kypson AP, et al. Significant reduction in annuloplasty operative time with the use of nitinol clips in robotically assisted mitral valve repair. J Thorac Cardiovasc Surg. 2007;133:1264-7.

11. Reade CC, Meadows WM Jr, Bower CE, Lalikos JF, Zeri RS, Wooden WA. Sutureless robot-assisted mitral valve repair: an animal model. Heart Surg Forum. 2003;6:254-7.

12. Gersch KA, Chu MWA, Neal JD, Narron JA, Nifong LW, Chitwood WR. Robotic mitral valve annuloplasty dehiscence: a comparison of the Nitinol U-Clip ${ }^{\mathrm{TM}}$ versus suture fixation. Abstract 10th New Era Cardiac Care Annual Meeting, January 5th-7th 2007, Huntington Beach, CA.

13. Morishige N, Hayashida Y, Ito N, Teshima H, Takeuchi K, Iwahashi H, et al. Application of a new suture material called the U-Clip for composite and sequential grafting with off-pump coronary bypass surgery. Heart Surg Forum. 2006;9:E861-5. 